\title{
Visfatin Gene Responses to 8 Weeks of Treadmill Running with or without Pistachio atlantica Liquid Extraction in Female Rat Tissues
}

\author{
Abbass Ghanbari-Niaki*, Navabeh Zare Kookandeh, Saleh Rahmati Ahmadabad, Rozita Fathi \\ Department of Physical Education and Sport Science, University of Mazandaran, Babolsar, Iran. \\ Email:"'ghanbara@umz.ac.ir,nnzare@gmail.com
}

Received June $9^{\text {th }}, 2012$; revised July $9^{\text {th }}, 2012$; accepted July $16^{\text {th }}, 2012$

\begin{abstract}
Visfatin, a novel adipokine, was revealed to be associated with obesity and to have insulin mimetic effect that is highly expressed in visceral adipose tissue. The aim of this study was to determine the liver and kidney visfatin relative gene expression. Twenty wistar rats ( 6 - 8 weeks old and 125 - $135 \mathrm{~g}$ weight) were used. Animals were randomly assigned into saline-control (SC), saline-training (ST), and Baneh-control (BC), and Baneh-training (BT). Training groups was given exercise on a motor-driven treadmill at $25 \mathrm{~m} / \mathrm{min}(0 \%$ grade) for $60 \mathrm{~min} /$ day and 5 days/week for eight weeks. Subjects were fed oral, with Baneh extraction and saline for four weeks. Visfatin relative gene expression was detected by Real-time PCR method. Also plasma was collected for glucose measurements. Results demonstrated that Baneh extraction significantly increase visfatin relative gene expression in liver $(\mathrm{P}<0.002)$ and increase not significantly in kidney tissue. Exercise training significantly reduce visfatin relative gene expression in liver $(\mathrm{P}<0.042)$, and reduce not significantly in kidney tissue. Plasma and liver glucose level increases by Baneh. Exercise training decreses visfatin relative gene expression and Baneh increases visfatin relative gene expression in liver and kidney. Also Baneh can increases plasma glucose and liver glucose and glycogen concentration probably due to high fatty acid and component.
\end{abstract}

Keywords: Visfatin; Female Rats; Treadmill Exercise; Pistachia atlantica

\section{Introduction}

Visfatin which is alternatively known as pre-B-cell colony-enhancing factor, or nicotinamide phosphoribosyltransferase. Revollo et al. found that mouse brown adipose tissue, liver, and kidney had the highest levels; mouse heart had intermediate levels; mouse white adipose tissue, lung, spleen, testis, and muscle had low levels; and mouse brain and pancreas had no visfatin protein expression levels [1]. It is now believed that visfatin actions can be endocrine, paracrine, and autocrine as well. These autocrine effects of visfatin may play an important role in regulating insulin sensitivity in the liver [2]. Plasma visfatin levels are elevated in patients with type2 diabetes and in obesity [3-5]. Physical exercise is a metabolic and neuroendocrine stressor that mobilizes lipids for energy and is a cornerstone treatment for obesity and diabetes [6-8]. Exercise also stimulates the secretion of proteins and cytokines from adipose tissues, including leptin, adiponectin and interleukins, all of which play an important role in metabolism $[9,10]$. Lee

"Corresponding author. et al. investigated the effect of 12 weeks' Aerobic exercise (intensity: 300 - 400 cal energy expenditure, duration: $45-50 \mathrm{~min} / \mathrm{session}$ and four days a week), that resulted visfatin significantly decrease in plasma of adolescents and Obese women [11]. Domieh et al. reported that 8 weeks' Aerobic exercise (intensity 65\% - 80\% HRmax, duration: $20-34 \mathrm{~min} / \mathrm{session}$ and 3 days a week), Causes visfatin significantly decrease in plasma of middle-aged men and a positive relationship between visfatin and plasma triglyceride levels and body fat were observed [12]. Also Haus et al. investigated that 12 weeks' endurance exercise (intensity $80 \% \mathrm{HRmax}$, duration: $60 \mathrm{~min} / \mathrm{session}$ and 5 days a week), Causes weight loss along with the significantly reduction in plasma visfatin levels [13].

More than two thousand years ago, doctors began using herbs to treat obesity; some of these herbs are included walnut, pistachio and silymarin. Over one hundred traditional chinese herb used for weight loss [14]. It has shown that walnut oil has properties that reduce blood total cholesterol in men [15]. The effect of silymarin on animals that fed with high-fat diets shown that 
this plant has positive effect on plasma lipoproteins profile [16].

Pistacia atlantica (Baneh) are plants of Anacardiaceae family that is rich in antioxidants and unsaturated fatty acid. This plant leave contains anti-oxidative compounds that reduces free radicals [17]. High levels of polyunsaturated fatty acids found in nuts can be caused by loss of appetite and its role in weight loss and plasma lipids is evident. However, no research was examined the effect of exercise on visfatin relative gene expression, in different tissues, also there is no report about the effects of Pistachia atlantica (Baneh) on visfatin gene expression. In this research, the possibility of exercising and Pistachia atlantica (Baneh) effect on relative gene expression of visfatin was studied.

\section{Materials and Methods}

\subsection{Plant Material}

The ripped fruit samples of Pistachia atlantica (Baneh) were collected from the fields of Maibod in the Yazd province of Iran, and were stored at $-18^{\circ} \mathrm{C}$ until use. Plant Material was identified by herbarium collection in Department of Physical Education and Sport Science, University of Mazandaran, Babolsar, Iran.

\subsection{Preparation of the Extracts}

The extraction was prepared according to the Hamdan et al. (2004) [18]. Briefly, the whole ripped and dried fruit of Pistachia atlantica (Baneh) (10 g) was coarsely powdered and mixed with $150 \mathrm{ml}$ of tap water and boiled for $45 \mathrm{~min}$ and then cooled at room temperature. After cooling, the mixture was filtered twice by using a Watman filter (No. 4 filter). The volume of the filtered solution was increased to $100 \mathrm{ml}$ with tap water so that $1 \mathrm{ml}$ was equivalent to $100 \mathrm{mg}$ of starting material. It has to be noted that we did not used distilled water on the basis of herbalist's recommendation. A fresh extraction was orally given at dose $100 \mathrm{mg} / \mathrm{kg}$ (7.5 ul/g of body weight).

\subsection{Animals}

All experiments involving the animals were conducted according to the policy of the Iranian convention for the protection of vertebrate animals used for experimental and other scientific purposes; and the protocol was approved by the Ethics Committee of the Sciences, University of Mazandaran (UMZ) and Babol University of Medical Sciences (BUMS, Mazandaran, Iran. Twenty wistar female rats ( 6 - 8 weeks old 125 - $135 \mathrm{~g}$ weight) were acquired from Pasteur's Institute (Amol, Mazandaran) and maintained in the Central Animal House of Faculty of Physical Education and Sports Science of UMZ.
Five rats were housed per cage (46-L volume) with a 12hour: 12-hour light-dark cycle. Temperature was maintained at $22^{\circ} \mathrm{C} \pm 1.4^{\circ} \mathrm{C}$. Diets (a pellet form) and water were provided ad libitum. Animals were randomly assigned into control $(\mathrm{n}=10)$ and training $(\mathrm{n}=10)$ groups. Rats were divided further into saline-control (SC), salinetraining (ST), and Baneh-control (BC), and Baneh-training (BT). The control group remained sedentary, whereas the training group underwent a moderate running exercise program.

\subsection{Exercise Training Protocol}

At first, the animals were familiarized with the rat treadmill apparatus, each day and for 4 days (the 14-lane motorized-driven treadmill was designed by the primary author (UMZ, Babolsar, Mazandaran, Iran). The exercise group was trained for 8 weeks using the same training methods previously described $[19,20]$. The rats were run at $25 \mathrm{~m} / \mathrm{min}$ for 60 minutes, $5 \mathrm{~d} / \mathrm{wk}$. The animals were killed 72 hours after the last exercise session. Food but not water was removed from the rat cages 4 hours before the sacrifices.

\subsection{Tissue Biopsies}

Seventy-two hours after the last training session, rats were anesthetized with intra peritoneal administration of a mixture of ketamine (30 - 50 mg/kg body weight) and xylazine ( $3-5 \mathrm{mg} / \mathrm{kg}$ body weight). Liver and kidney were excised, cleaned, divided into two pieces, washed in ice-cold saline, and immediately frozen in liquid nitrogen and stored at $-80^{\circ} \mathrm{C}$ until RNA extraction.

\subsection{RNA, cDNA Synthesis and Real-Time PCR}

Total RNA was extracted from 80 to $100 \mathrm{mg}$ of tissue using RNA purification kits (AccuZol, Bioneer, Cat. No: k3090). Complementary DNA (cDNA) was extended from $1 \mu \mathrm{l}$ oligo-(dt) $)_{18}$ primers $(0.25 \mu \mathrm{g}$ per reaction) using cDNA synthesis kit (AccuPower RT PreMix, Bioneer, Cat. No: k2041-B) according to the manufacturer's instructions. cDNA concentration was 1 to $2 \mathrm{ng} / 25 \mu \mathrm{l}$ reaction. Real-time quantitative PCR was performed using Quanti Fast SYBR Green PCR Kit (Cat. No. 204052; Qiagen, $\mathrm{GmbH}$, Germany) in using $15 \mu \mathrm{l}$ reaction containing $0.5 \mu \mathrm{l}$ single-strand cDNA, $7.5 \mu \mathrm{l}$ Master Mix, 1 $\mu \mathrm{l}$ of the each forward and reverse primers $(5 \mathrm{pmol} / \mu \mathrm{l})$ and $5 \mu \mathrm{dH} 2 \mathrm{O}$. Visfatin sense primer; 5'-AGCGGCAGA GCACAGTACCATA-3' and antisense primer were 5'CCACAGACACAGGCACTGATGA-3' (NM177928, $101 \mathrm{bp}$ ), respectively [21]. The $\beta$-actin sense and antisense primers were; 5'-TATCGGCAATGAGCGGTTC C-3' and 5'-AGCACTGTGTTGGCATAGAGG-3' (NM_ 
031144, $145 \mathrm{bp}$ ), respectively [22].

Real-time PCR reactions were performed using the Rotor Gene 3000 real time PCR system from Corbett using following program: step $1: 95^{\circ} \mathrm{C}$ for $5 \mathrm{~min}$ and step 2: 40 cycle of $95^{\circ} \mathrm{C}$ for $10 \mathrm{sec}$ and $60^{\circ} \mathrm{C}$ for $30 \mathrm{sec}$. The last heating step in phase 2 was carried out for generation of a melting curve of the product. The amplicons were melted at the rate of $0.1{ }^{\circ} \mathrm{C} / \mathrm{s}$ to generate the high resolution melting profile.

\subsection{Glucose, Glycogen}

Plasma glucose was determined by an enzymatic, colorimetric method (glucose oxidase-amino antipyrine; Pars Azmoun, Tehran, Iran), and the intra-assay coefficient of variation and sensitivity were $1.2 \%$ and 5.0 $\mathrm{mg} / \mathrm{dl}$, respectively.

Liver glycogen was also determined by (Glycogen Colorimetric kit, Nanjing, China), and the coefficient of variation and sensitivity were $48 \%$ and $0.09 \mathrm{mg} / \mathrm{dl}$, respectively.

\subsection{Statistical Analysis}

The data were analyzed by using a comparative threshold cycle method (CT). CT for each sample determined by implying a Rotor-Gene 3000 Software. Briefly, $\Delta$-CT value calculated by taking the $\mathrm{CT}$ of the visfatin gene and subtracting it from CT of $\beta$-actin. The $\Delta \Delta$-CT was calculated by subtracting the $\Delta$-CT (sample) values from the $\Delta$-CT (control). The relative quantification was then calculated by the expression $2^{-\Delta \Delta \mathrm{CT}}$ [23]. The Kolmogorov-Smirnov test was used to determine the normality of distribution, and variables were found to be normally distributed. All results are expressed as means \pm SEM. Statistical analysis were performed using a one way analysis of variance. Least significant difference post hoc test was used in the event of a significant $(\mathrm{P}<0.05) \mathrm{F}$ ratio. All statistical analysis was performed with SPSS (Version 16; SPSS, Chicago, IL).

\section{Results}

Visfatin relative gene expression in liver and kidney were determined in female rats. Data analysis revealed a significant difference in liver visfatin mRNA relative abundance between groups $(\mathrm{F}=6.45, \mathrm{P}<0.005)$ (Figure 1). Using a suitable post hoc test data were showed that liver relative expression of visfatin was higher in $\mathrm{BC}$ $(3.9449 \pm 0.86)$ group when compared with other groups at the end of program (Figure 1). In this regard, using a suitable univariate test, data was showed that Baneh increases the visfatin relative mRNA expression. In addition relative expression of visfatin mRNA in control groups was significantly higher than trained groups. Also in kidney tissue, a no significant difference was found in relative expression of visfatin mRNA between groups (F $=0.754, \mathrm{P}<0.536)$ (Figure 2). In this regard, the visfatin mRNA relative abundance was lower in saline-treated animals when compared with Baneh-treated groups (Figure 2). Data analysis revealed significant difference liver glucose concentration between groups $(\mathrm{F}=5.596, \mathrm{P}<$ $0.05)$. Liver glucose was higher in $\mathrm{BC}$ compared with $\mathrm{SC}$ group at the end of program $(\mathrm{P}<0.015)$ and liver glucose was higher in BT compared with ST group $(\mathrm{P}<0.025)$ (Figure 3). Also data showed plasma glucose was higher in $\mathrm{BC}$ compared with $\mathrm{SC}$ group at the end of program (P $<0.02$ ) (Figure 4) and liver glycogen changed not significantly in all groups (Figure 5).

\section{Discussion}

To our knowledge, this is the first report to demonstrate alterations of female rat liver and kidney visfatin relative gene expression in response to a treadmill running and Baneh crud extraction regime. The major findings of the present study were a higher visfatin relative gene expression in control liver and kidney than trained groups.

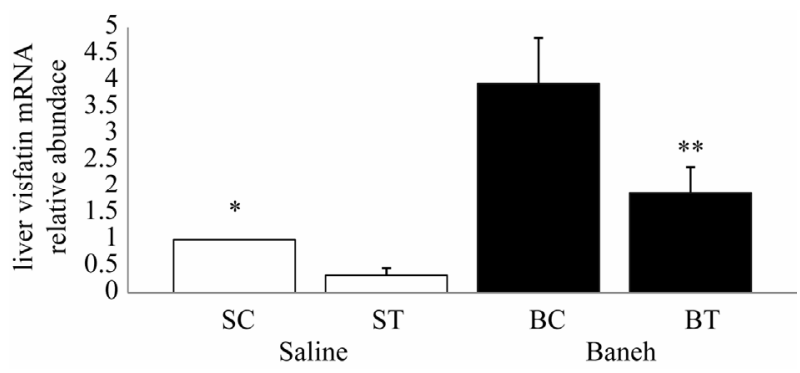

Figure 1. Real-time PCR of liver visfatin relative mRNA expression in saline-control (SC), saline-training (ST), Baneh-control (BC), and Baneh-training (BT) wild-type female rats. Data expressed as mean \pm SEM. Each column is for each group and 5 rats per each group. ${ }^{*} \mathrm{SC}$ vs $\mathrm{BC},(\mathrm{P}<$ 0.004); ${ }^{* *}$ CB vs BT, $($ P $<0.031)$.

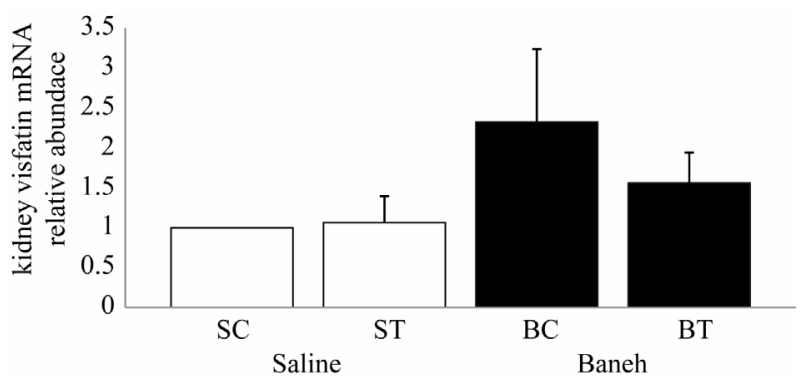

Figure 2. Real-time PCR of kidney visfatin relative mRNA expression in saline-control (SC), saline-training (ST), Baneh-control (BC), and Baneh-training (BT) wild-type female rats. Data expressed as mean \pm SEM. Each column is for each group and 5 rats per each group. 


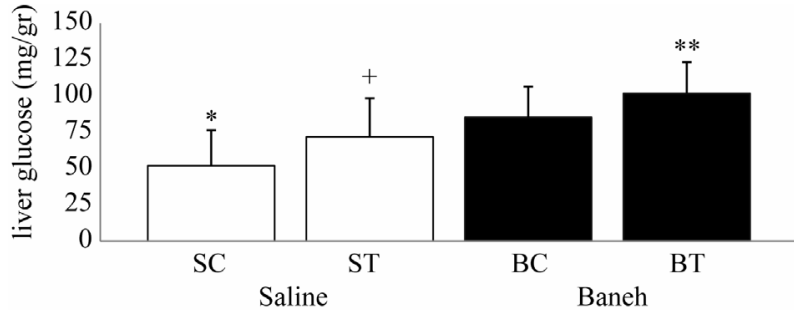

Figure 3. Liver glucose concentration $(\mathrm{mg} / \mathrm{dl})$ in salinecontrol (SC), saline-training (ST), Baneh-control (BC), and Baneh-training (BT) wild-type female rats. Wild-type female rats Data expressed as mean $\hat{A} \pm$ SEM. Each column is for each group and 5 rat per group. " $\mathrm{SC}$ vs $\mathrm{BC},(\mathrm{P}<0.015)$; ${ }^{* *}$ SC vs BT, $(\mathrm{P}<0.001)$; ${ }^{+}$ST vs BT, $(\mathrm{P}<0.025)$.

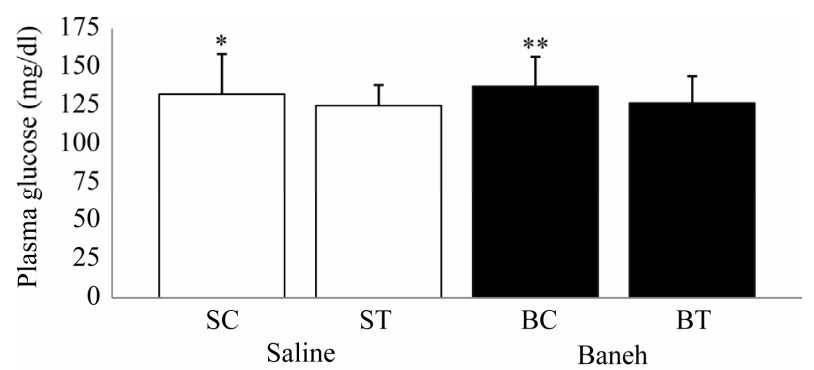

Figure 4. Plasma glucose concentration $(\mathrm{mg} / \mathrm{dl})$ in salinecontrol (SC), saline-training (ST), Baneh-control (BC), and Baneh-training (BT) wild-type female rats. Wild-type female rats data expressed as mean $\hat{A} \pm$ SEM. Eachcolumn is for each group and 5 rats per group. ${ }^{*} \mathrm{SC}$ vs $\mathrm{BC},(\mathrm{P}<0.02)$; ${ }^{* *}$ ST vs BC, $(\mathrm{P}<0.04)$.

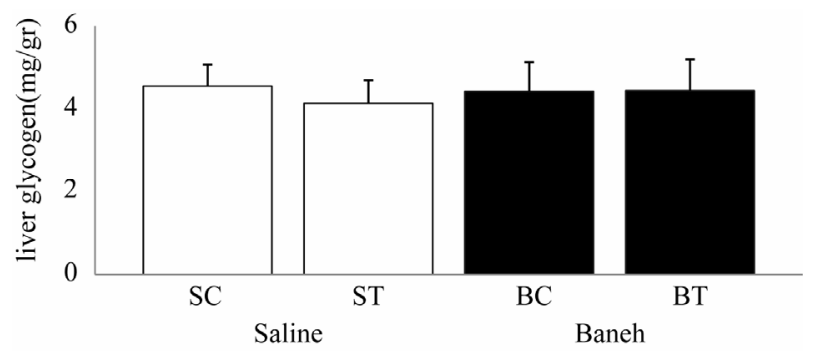

Figure 5. Liver glycogen concentration (mg/gr) in salinecontrol (SC), saline-training (ST), Baneh-control (BC), and Baneh-training (BT) wild-type female rats. Wild-type female rats Data expressed as mean $\hat{A} \pm$ SEM. Each column is for each group and 5 rat per group.

Other finding was a lower visfatin mRNA relative abundance in saline-treated liver and kidney of rats when compared with Baneh-treated animals. Revollo et al. found that mouse brown adipose tissue, liver, and kidney had the highest levels; mouse heart had intermediate levels; mouse white adipose tissue, lung, spleen, testis, and muscle had low levels; and mouse brain and pancreas had no visfatin protein expression levels [1].

In this study we detected visfatin relative gene expression in several tissues including liver, and kidney by
Real-time PCR method that are concurrent with previous reported in tissues visfatin gene expression. In the present study, exercise reduced visfatin mRNA relative abundance in liver tissue (Figure 1). More recent studies by Revollo et al. have shown that visfatin is homologous to the enzyme nicotinamide phosphoribosyl transferase that is responsible for intracellular and extracellular nicotinamide adenine dinucleotide biosynthesis, and is involved in insulin secretion from pancreatic islets [1]. In recent year several studies was made on visfatin Lee et al. investigated the effect of 12 weeks' Aerobic exercise (intensity: 300 - 400 cal energy expenditure, duration: 45 $50 \mathrm{~min} / \mathrm{session}$ and four days a week), that resulted visfatin significantly decrease in plasma of adolescents and Obese women [11]. Domieh et al. reported that 8 weeks' Aerobic exercise (intensity 65\% - 80\% HRmax, duration: $20-34 \mathrm{~min} / \mathrm{session}$ and 3 days a week), Causes visfatin significantly decrease in plasma of Middle-aged men and a positive relationship between visfatin and plasma triglyceride levels and body fat were observed [12]. Also Haus et al. investigated that 12 weeks' endurance exercise (intensity 80\% HRmax, duration: $60 \mathrm{~min} / \mathrm{session}$ and 5 days a week), Causes Weight loss Along with the significantly reduction in plasma visfatin levels [13]. Previous research showed that pistachios are rich in essential oils [24]. Baneh is oil seed and has abundant fatty acids. Analysis of the Pistachia atlantica varmutica essential oil by GC-MS method, shown that it composed of $\alpha$ pinene $(70 \%), \beta$-pinene $(1.94 \%)$, 3-carene $(0.2 \%)$, carveol $(2.18 \%)$, epoxypinene $(2.15 \%)$, limonene oxide $(9 \%)$, myrtenol (5.31\%), limonene (0.62\%), citral (5.72\%), $\alpha$ phellandrene $(0.2 \%)$, and $\beta$-myrcene $(0.3 \%)$ [24].

Data collected by using a GC-MS has shown that our used material had main following compositions; hexadecenoic acid $(7.52 \%)$, Palmitinic acid $(28.86 \%)$, transOleic acid (49.28\%), n-Octadecanoic acid (3.87\%). It is possible that the existence of a higher trans oleic acid and Palmitinic acid contents were enough to act as a high fat liquid extraction to increase visfatin expression in Baneh groups. The total amount of essential oil obtained was $22 \% \mathrm{v} / \mathrm{w}$ which is higher than any other species of the genus pestacia [25].

It has been shown that monounsaturated FFA oleate (C18:1) and saturated FFA palmitate (C16:0) reduces visfatin gene expression in cultured 3T3-L1 adipocytes or preadipocytes. Dose-response studies demonstrated that addition of $0.125 \mathrm{mmol} / \mathrm{L}$ oleate and palmitate to 3T3-L1 adipocytes decreased visfatin mRNA expression significantly $(78 \%, 77 \%$, respectively, relative to untreated control), and further to $65 \%$ (relative to untreated control), and $55 \%$ (relative to untreated control) at 1.0 mmol/L FFA. Furthermore, the suppression on preadipocytes was similar to that of adipocytes, which reached 
a maximal reduction of $44 \%$ (oleate) and $47 \%$ (palmitate) at $1.0 \mathrm{mmol} / \mathrm{L}$ FFA [26]. In pre-adipocytes, visfatin expression decreased by $50 \%$ with palmitate and $30 \%$ with oleate [27]. One existing study has focused on the effects of unsaturated free fatty acids on plasma concentration of adipokine peptide: Cooper et al showed that dietary fatty acid composition significantly reduce plasma PYY concentration and can increases plasma ghrelin concentration that are not significant [28].

Siahanidou et al. showed that Serum visfatin levels were significantly higher in the +LCPUFA (arachidonic and docosahexaenoic acid) than in the -LCPUFA (without LCPUFA) group $(\mathrm{P}<0.001)$ and correlated positively with body weight $(\mathrm{P}<0.02)$, total cholesterol $(\mathrm{P}<$ $0.01)$, high-density lipoprotein cholesterol (HDL-C) $(\mathrm{P}<$ $0.001)$, and adiponectin levels $(\mathrm{P}<0.03)$, but not with indices of insulin sensitivity [29].

The important point of this research is increase of visfatin relative gene expression by Baneh in liver and kidney that probably is due to Baneh high fatty acid (Figures 1 and 2). It probably could be because of Pistachia atlantica including several saturated and unsaturated fatty acids and material, with variety percentage. Also tissue in our study was different.

In summary, this investigation was about effect of eight weeks endurance training and Pistachia atlantica extraction on relative expression of visfatin in female rats and this study confirms that visfatin expresses in tissue such as liver and kidney. The main finding of the present study were less and significant relative expression of visfatin mRNA in liver, less and no significant relative expression of visfatin mRNA in kidney tissues following treadmill running program in female rats. Others main finding was lower and significant visfatin relative gene expression in saline treated animals compared with Baneh groups. Our study show that, Pistachia atlantica (Baneh), can probably increase visfatin relative gene expression in liver and kidney tissue due to its essential fatty acids.

\section{REFERENCES}

[1] J. R. Revollo, A. Korner, K. F. Mills, A. Satoh, T. Wang, A. Garten, B. Dasgupta, Y. Sasaki, C. Wolberger, R. R. Townsend, J. Milbrandt, W. Kiess and S. Imai, "Nampt/ $\mathrm{PBEF} /$ Visfatin Regulates Insulin Secretion in Beta Cells as a Systemic NAD Biosynthetic Enzyme," Cell Metabolism, Vol. 6, No. 5, 2007, pp. 363-375. doi:10.1016/j.cmet.2007.09.003

[2] V. Skop, K. Kontrová, V. Zídek, M. Pravenec, L. Kazdová, K. Mikulík, J. Sajdok and J. Zídková, “Autocrine Effects of Visfatin on Hepatocyte Sensitivity to Insulin Action," Physiological Research, Vol. 59, No. 4, 2010, pp. 615-618.
[3] E. Garcia-Fuentes, J. M. Garcia-Almeida, J. Garcia-Arnes, S. Garcia-Serrano, J. Rivas-Marin, J. L. Gallego-Perales, G. Rojo-Martínez, L. Garrido-Sánchez, F. J. BermudezSilva, F. Rodríguez de Fonseca and F. Soriguer, "Plasma Visfatin Concentrations in Severely Obese Subjects Are Increased after Intestinal Bypass," Obesity (Silver Spring), Vol. 15, No. 10, 2007, pp. 2391-2395. doi:10.1038/oby.2007.284

[4] M. P. Chen, F. M. Chung, D. M. Chang, J. C. Tsai, H. F. Huang, S. J. Shin and Y. J. Lee, "Elevated Plasma Level of Visfatin/Pre-B Cell Colony-Enhancing Factor in Patients with Type 2 Diabetes Mellitus," Journal of Clinical Endocrinology \& Metabolism, Vol. 91, No. 1, 2006, pp. 295-299. doi:10.1210/jc.2005-1475

[5] J. Berndt, N. Kloting, S. Kralisch, P. Kovacs, M. Fasshauer, M. R. Schon, M. Stumvoll and M. Blüher, "Plasma Visfatin Concentrations and Fat Depot-Specific mRNA Expression in Humans," Diabetes, Vol. 54, No. 10, 2005, pp. 2911-2916. doi:10.2337/diabetes.54.10.2911

[6] E. F. Coyle, "Physical Activity as a Metabolic Stressor," American Journal of Clinical Nutrition, Vol. 72, No. 2, 2000, pp. 512S-520S.

[7] B. Kiens, "Skeletal Muscle Lipid Metabolism in Exercise and Insulin Resistance," Physiological Reviews, Vol. 86, No. 1, 2006, pp. 205-243. doi:10.1152/physrev.00023.2004

[8] A. C. Hackney, "Exercise as a Stressor to the Human Neuroendocrine System," Medicina (Kaunas), Vol. 42, No. 10, 2006, pp. 788-797.

[9] V. B. O’Leary, A. E. Jorett, C. M. Marchetti, F. Gonzalez, S. A. Phillips, T. P. Ciaraldi and J. P. Kirwan, "Enhanced Adiponectin Multimer Ratio and Skeletal Muscle Adiponectin Receptor Expression Following Exercise Training and Diet in Older Insulin-Resistant Adults," American Journal of Physiology-Endocrinology and Metabolism, Vol. 293, No. 1, 2007, pp. E421-E427. doi:10.1152/ajpendo.00123.2007

[10] J. Polak, E. Klimcakova, C. Moro, N. Viguerie, M. Berlan, J. Hejnova, B. Richterova, I. Kraus, D. Langin and V. Stich, "Effect of Aerobic Training on Plasma Levels and Subcutaneous Abdominal Adipose Tissue Gene Expression of Adiponectin, Leptin, Interleukin 6, and Tumor Necrosis Factor in Obese Women," Metabolism, Vol. 25, No. 10, 2006, pp. 1375-1381. doi:10.1016/j.metabol.2006.06.008

[11] K. J. Lee, Y. A. Shin, K. Y. Lee, T. W. Jun and W. Song, "Aerobic Exercise Training-Induced Decrease in Plasma Visfatin and Insulin Resistance in Obese Female Adolescents," International Journal of Sport Nutrition and Exercise Metabolism, Vol. 20, No. 4, 2010, pp. 275-281.

[12] A. M. Domieh and A. Khajehland, "Effect of 8 Weeks Endurance Training on Plasma Visfatin in Middle-Aged Men," Brazilian Journal of Biomotricity, Vol. 4, No. 3, 2010, pp. 174-179.

[13] J. M. Haus, T. P. Solomon, C. M. Marchetti, V. B. O'Leary, L. M. Brooks, F. Gonzalez and J. P. Kirwan, "Decreased Visfatin after Exercise Training Correlates 
with Improved Glucose Tolerance," Medicine and Science in Sports and Exercise, Vol. 41, No. 6, 2009, pp. 1255-1260. doi:10.1249/MSS.0b013e318195bad5

[14] W. X. Tian, L. C. Li, X. D. Wu and C. C. Chen, "Weight Reduction by Chinese Medicinal Herbs May Be Related to Inhibition of Fatty Acid Synthase," Life Sciences, Vol. 74, No. 19, 2004, pp. 2389-2399. doi:10.1016/j.1fs.2003.09.064

[15] J. Sabate, G. E. Fraser, K. Burke, S. F. Knutsen, H. Bennett and K. D. Lindsted, "Effects of Walnuts on Serum Lipid Levels and Blood Pressure in Normal Men," New England Journal of Medicine, Vol. 328, No. 9, 1993, pp. 603-607. doi:10.1056/NEJM199303043280902

[16] R. Vecera, A. Zacharova, J. Orolin, N. Skottova and P. Anzenbacher, "The Effect of Silymarin on Expression of Selected ABC Transporters in the Rat," Veterinary Medicine, Vol. 56, No. 2, 2011, pp. 59-62.

[17] N. Benhammou, F. Bekkara and T. Panovska, "Antioxidant and Antimicrobial Activities of the Pistacia Lentiscus and Pistacia Atlantica Extracts," Pharmacy and Pharmacology, Vol. 2, No. 2, 2008, pp. 22-28.

[18] I. I. Hamdan and F. U. Afifi, "Studies on the in Vitro and in Vivo Hypoglycemic Activities of Some Medicinal Plants Used in Treatment of Diabetes in Jordanian Traditional Medicine," Journal of Ethnopharmacology, Vol. 93, No. 1, 2004, pp. 117-121. doi:10.1016/j.jep.2004.03.033

[19] A. Ghanbari-Niaki, B. M. Khabazian, S. A. HossainiKakhak, F. Rahbarizadeh and M. Hedayati, "Treadmill Exercise Enhances ABCA1 Expression in Rat Liver," Biochemical and Biophysical Research Communications, Vol. 361, No. 4, 2007, pp. 841-846. doi:10.1016/j.bbrc.2007.07.100

[20] B. M. Khabazian, A. Ghanbari-Niaki, A. R. SafarzadehGolpordesari, M. Ebrahimi, F. Rahbarizadeh and H. Abednazari, "Endurance Training Enhances ABCA1 Expression in Rat Small Intestine," European Journal of Applied Physiology, Vol. 107, No. 3, 2009, pp. 351-358. doi:10.1007/s00421-009-1133-3

[21] T. Josephs, H. Waugh, I. Kokay, D. Grattan and M. Thompson, "Fasting-Induced Adipose Factor Identified as a Key Adipokine That Is Up-Regulated in White Adipose Tissue during Pregnancy and Lactation in the Rat,"
Journal of Endocrinology, Vol. 194, No. 2, 2007, pp. 305312. doi:10.1677/JOE-07-0158

[22] X. Gao and S. Yuan, "High Density Lipoporteins-Based Therapies for Cardiovascular Disease," Journal of Cardiovascular Disease Research, Vol. 1, No. 3, 2010, pp. 99-103. doi:10.4103/0975-3583.70898

[23] K. J. Livak and T. D. Schmittgen, "Analysis of Relative Gene Expression Data Using Real-Time Quantitative PCR and the 2(-Delta Delta C(T)) Method," Methods, Vol. 25, No. 4, 2001, pp. 402-408. doi:10.1006/meth.2001.1262

[24] N. Gourine, I. Bombarda, M. Yousfi and E. M. Gaydou, "Chemotypes of Pistacia Atlantica Leaf Essential Oils from Algeria," Natural Product Communications, Vol. 5, No. 1, 2010, pp. 115-120.

[25] A. Delazar, R. G. Reid and S. D. Sarker, "GC-MS Analysis of the Essential Oil from the Oleoresin of Pistacia Atlantica Var mutica," Chemistry of Natural Compounds, Vol. 40, No. 1, 2004, pp. 24-27. doi:10.1023/B:CONC.0000025459.72590.9e

[26] Y. Wen, H. W. Wang, J. Wu, H. L. Lu, X. F. Hu and K. Cianflone, "Effects of Fatty Acid Regulation on Visfatin Gene Expression in Adipocytes," Chinese Medical Journal, Vol. 119, No. 20, 2006, pp. 1701-1708.

[27] R. Maclaren, W. Cui and K. Cianflone, "Visfatin Expression Is Hormonally Regulated by Metabolic and Sex Hormones in 3T3-L1 Pre-Adipocytes and Adipocytes," Diabetes, Obesity and Metabolism, Vol. 9, No. 4, 2009, pp. 490-497. doi:10.1111/j.1463-1326.2006.00625.x

[28] J. A. Cooper, A. C. Watras, C. M. Paton, F. H. Wegner, A. K. Adams and D. A. Schoeller, "Impact of Exercise and Dietary Fatty Acid Composition from a High-Fat Diet on Markers of Hunger and Satiety," Appetite, Vol. 56, No. 1, 2011, pp. 171-178. doi:10.1016/j.appet.2010.10.009

[29] T. Siahanidou, A. Margeli, A. Kappis, I. Papassotiriou and H. Mandyla, "Circulating Visfatin Levels in Healthy Preterm Infants Are Independently Associated with HighDensity Lipoprotein Cholesterol Levels and Dietary Long-Chain Polyunsaturated Fatty Acids," Metabolism, Vol. 60, No. 3, 2010, pp. 389-393. doi:10.1016/j.metabol.2010.03.002

\section{List of Abbreviations}

Pistachia atlantica (Baneh);

Saline-control (SC);

Baneh-control (BC);

Saline-training (ST);

Baneh-training (BT). 